DOI 10.37882/2223-2982.2020.11-2.03

\title{
К ВОПРОСУ О НЕОБХОДИМОСТИ СОЗДАНИЯ ЯЗЫКОВОЙ СРЕДЫ В РОССИЙСКИХ ВУЗАХ (ДЛЯ СТУДЕНТОВ, ИЗУЧАЮЩИХ КИТАЙСКИЙ ЯЗЫК)
}

\section{ON THE NEED TO CREATE A LANGUAGE ENVIRONMENT IN RUSSIAN UNIVERSITIES (FOR STUDENTS STUDYING CHINESE) \\ N. Bogdanova \\ E. Solntseva}

Summary: In the process of learning a foreign language, the language environment is an important factor. This article presents arguments about the need to create an artificial language environment for students studying Chinese in Russia. The authors give examples of using modern technologies both for viewing and listening to materials in Chinese. Special attention is paid to the competencies of Russian Chinese language teachers, as well as the methods of conducting classes. The paper shows the method of creating a language environment in the classroom and outside the classroom. In the article, the authors consider modern teaching methods and come to the conclusion that creating a language environment will allow students to gain the knowledge and skills necessary for further work, remove the psychological barrier, and quickly adapt to the country of the language being studied.

Keywords: language environment; creating a language environment; teaching Chinese; teaching methods; Chinese as a foreign language, language acquisition.

\author{
Богданова Надежда Андреевна \\ К.и.н., старший преподаватель, Российский \\ Университет Дружбы Народов, Москва \\ Nad973@yandex.ru \\ Солнцева Елена Георгиевна \\ К.филол.н., доцент, Российский Университет \\ Дружбы Народов, Москва \\ solntseva-elena@yandex.ru
}

Аннотация: В процессе изучения иностранного языка важным фактором является языковая среда. В данной статье приведены доводы о необходимости создания искусственной языковой среды для студентов, изучающих китайский язык в России. Авторы приводят примеры использования современных технологий как для просмотров, так и для прослушивания материалов на китайском языке. Особое внимание уделяется компетенциям российских преподавателей китайского языка, а также методам проведения занятий. В работе показана методика создания языковой среды на занятиях и вне класса. В статье авторы рассматривают современные методики преподавания, приходят к заключению, что создание языковой среды позволит студентам получить знания и навыки, необходимые для дальнейшей работы, снять психологический барьер, быстро адаптироваться в стране изучаемого языка.

Ключевые слова: языковая среда; создание языковой среды; обучение китайскому языку; методика преподавания; китайский язык как иностранный, усвоение языкового материала.
Я зыковая среда может быть как естественной, когда обучающийся находится в стране изучаемого языка, так и искусственной, которая создается в условиях ее отсутствия с помощью различных вспомогательных средств. В первую очередь, для студентов, начинающих изучать китайский язык в российских вузах, необходимо создать на занятиях искусственную языковую среду. Если раньше роль преподавателя заключалась только в составлении диалогов «в рамках изучаемых тем самого преподавателя с учащимися» [Фурманова, 2014], то с развитием виртуальных ресурсов возможности создания полноценной языковой среды расширились.

Приступив к обучению на начальном уровне, преподавателю необходимо выработать у студентов чувство языка, которое включает способность воспринимать произношение, семантику, грамматику и интонацию языка. Чувство языка формируется в языковой практике постепенно, поэтому необходимо уже в начале обучения сознательно развивать чутье языка с помощью таких языковых практик как письмо и чтение. Ведь именно при длительном опыте чтения и письма «мозг вынужден обрабатывать огромное количество языковой информации в ее звуковом и графическом отображении». [Электронный ресурс/ http://poligloty.net/chuvstvojazyka/]

Еще одна из важных форм развития чувства языка создание речевой среды. В практике известны случаи, когда в ходе изучения языка студенты, отлично зная правила грамматики и фонетики, не могут применить свои навыки в общении с носителем языка. Вот почему преподавателям уже на начальном этапе обучения необходимо вводить на занятиях элементы речевой среды, например, в виде обсуждения прочитанного текста с дальнейшей дискуссией. Такая практика способствует выработке грамотной речи, помогает студентам свободно излагать мысли и доводы с точки зрения грамматики, словообразования, морфологии, а также смысловой составляющей.

Языковая среда является многосторонней и многоуровневой, но для студентов она в основном включает в 
себя языковую среду внутри и вне класса.

Для создания благоприятной языковой среды при изучении китайского языка необходимы три ключевых аспекта: ведение занятий на китайском языке, применении коммуникативного принципа и применение современных методов обучения.

\section{1. Преподавание на китайском языке}

Чтобы студенты привыкли к фонетике изучаемого языка, преподавателю необходимо вести занятия на китайском языке. На начальном этапе обучения преподаватель может давать объяснения предмета или лица на китайском языке простыми фразами, чтобы студенты поняли смысл. Например, слово图书馆 (túshūguăn -библиотека) можно объяснить как 图书馆是人们借书还 书的地方(библиотека - это место, где люди берут и куда возвращают книги). В самом начале обучения преподаватель может дублировать высказывания на русский языке, постепенно оставляя только китайский. Полезно также использовать наглядный материал, например, плакаты с темой урока, фонетической транскрипцией, схемой предложений. Это может не только помочь студентам понять и освоить содержание изучаемого материала, но и привлечь их внимание, вызвать интерес к учебе, активизировать атмосферу на занятиях, а также повысить эффективность преподавания.

\section{2. Применение коммуникативного принципа}

Коммуникация является важной составляющей формирования языковой среды. Задача преподавателя полностью переключить студентов с пассивного получения знаний, заинтересовать, научить учащихся активно пользоваться полученными знаниями и навыками. Для этого на занятиях преподавателю нужно создавать как можно больше коммуникационных возможностей, например, разыгрывание сценок и диалогов, обсуждение прочитанного текста, пересказ текста, а также поощрение активной работы в группах и т. д. Таким образом можно максимально проявить роль языковой среды и улучшить эффект обучения.

Еще одной коммуникативной возможностью являются уроки, которые проводит носитель языка. Такие занятия помогают студентам снять зажатость, скованность, боязнь общения на иностранном языке, а также позволяют студентам узнавать новые слова и выражения, которые употребляются в повседневной речи.

\section{3. Применение современных методов обучения}

Современный процесс обучения иностранному языку неразделим с применением современных технических средств. Так, мультимедийное учебное оборудование и современные технические средства создают учебный контент в форме изображения или звука, движения или покоя, картин или текста, чтобы учащиеся могли понять, что такое реальная языковая среда и у них появилось желание использовать в разговорной практике китайский язык. Мультимедийное оборудование также помогает преподавателю больше времени уделять практическим занятиям на китайском языке, что способствует улучшению качества образования в аудитории.

Очень важным моментом в обучении китайскому языку является создание языковой среды вне класса. Основываясь на собственном опыте преподавания китайского языка, хочется выделить организацию встреч со студентами - китайцами, просмотр фильмов/ новостей на иностранном языке, организацию и проведение конкурсов.

1. Проведение мероприятий со студентами - китайцами (чаепитие, поход в музей, китайское кафе).

Живое общение невозможно заменить только педагогическими приемами. Для студентов, изучающих китайский язык, общение со сверстниками - носителями языка является очень ценным опытом в освоении языка. Например, совместный поход в Музей Востока или китайское кафе, может помочь российским студентам не только лучше узнать культуру, искусство или кулинарию Китая, но и получить объяснения непосредственно от носителей языка.

2. Организация просмотра китайских фильмов и телевидения

Еще одним важным компонентом для изучения языка является знание истории и культуры страны изучаемого языка. В наше время всевозможных технических новинок, социальных сетей, обойтись только чтением уже невозможно. Новое поколение студентов не может не использовать технические средства или социальные сети. Поэтому преподаватель для создания внеклассной языковой среды, может привлекать в качестве наглядного пособия фильмы и новостные передачи. Обычно такие просмотры проходят вне аудиторных занятий, в более неформальной обстановке. Часто российские студенты приглашают на такие мероприятия друзей - китайцев, что помогает в создании языковой среды. Просмотр исторических художественных фильмов знакомит студентов с историческим аспектом, речью, нормами поведения, просмотр современных передач помогает студентам узнавать неологизмы нашего времени. Новостные программы не только способствуют расширению знаний в области геополитики, но и помогают в закреплении особого вида лексики - политической. Проведение подобных мероприятий помогает учащимся не только улучшить восприятие китайского языка на слух, 
расширить лексический запас, но и способствует лучшему пониманию культуры, истории и современной жизни страны изучаемого языка, повышает интерес к дальнейшему обучению.

\section{3. Организация конкурсов по китайскому языку}

Организация конкурса стимулирует студентов на активное участие и победу в соревнованиях, развивает здоровую конкуренцию, азарт. По своему содержанию конкурсы могут быть различными, например, конкурс чтецов или песенный, викторины. Мероприятия могу носить как местный характер, то есть проводиться в рамках одной группы, факультета, вуза, так и иметь межвузовский, национальный статус. Обычно конкурсы проводят в одном и том же месте, в одно и то же время, хотя содержание и правила соревнований могут меняться в зависимости от уровня. Что касается наград и призов, то для конкурса, проводимого в одной группе, это могут быть традиционные китайские сладости. А если речь идет о межвузовском или национальном уровне, то главным призом может стать годовая стажировка в китайский вуз. Участие в конкурсах не только стимулирует студентов получить отличные знания, обнаружить пробелы в образовании, но и помогает им, как будущим специалистам, развиваться.

Таким образом, создание языковой среды как на занятиях, так и вне класса играет важную роль в процессе обучения китайскому языку. При этом, использование перечисленных приемов для создания искусственной языковой среды, наполнение их лингвокультурным материалом, проведение или подготовка студентов к конкурсу, организация внеклассных мероприятий полностью лежат на плечах преподавателей. Часто меняющиеся реалии нашей жизни, смещение акцентов способствуют постоянному обновлению преподавателем визуальных или аудиоматериалов, написанию новых методических пособий, выбора литературных произведений для внеклассного чтения на китайском языке. Еще одной важной составляющей для лучшего обучения студентов является сведение к минимуму психологического барьера, а именно: создание дружелюбной атмосферы на занятиях, поощрение к свободному общению на китайском языке, чтобы в дальнейшем, прибыв в Китай, было проще адаптироваться к естественной языковой среде.

\section{ЛИТЕРАТУРА}

1. Азимов Э.Г., Щукин А.Н. Новый словарь методических терминов и понятий (теория и практика обучения языкам). - М.: Издательство ИКАР, 2009. $448 \mathrm{C}$.

2. Иванова Т.В., Киреева 3.Р., Сухова И.А. Технологии и методики обучения иностранным языкам: учебное пособие для студентов направления подготовки «Филологическое образование». Часть І. Уфа: Изд-во БГПУ. 2009. 186 с.

3. Орехова И.А. Языковая среда и среда общения. / В сборнике: Филологическое образование в современных исследованиях: лингвистический и методический аспекты. Материалы Международной научно-практической конференции. Гос. ИРЯ им. А.С. Пушкина. 2015. С. 412-415.

4. Лебедева 0.А. Чувство языка как компонент коммуникативной компетенции (в аспекте соотношения понятий) [Электронный ресурc] // URL: https:// cyberleninka.ru/article/n/chuvstvo-yazyka-kak-komponent-kommunikativnoy-kompetentsii-v-aspekte-sootnosheniya-ponyatiy (дата 0бращения 12.10.2020)

5. Фурманова М.И. УДК:378.046.7 Языковая/речевая среда урока иностранного языка на основе информационно/коммуникационной среды - стимулирующий фактор усвоения знаний и формирования коммуникативных умений [Электронный ресурс] // URL: https://cyberleninka.ru/article/n/yazykovayarechevaya-sreda-uroka-inostrannogo-yazyka-na-osnove-informatsionno-kommunikatsionnoy-sredy-stimuliruyuschiy-faktor) (дата 0бращения 10.10.20

6. Чекун 0.А. Роль инновационных технологий в создании языковой среды. // в сборнике Современное языковое образование: инновации, проблемы, решения. М., 2014. С.100-104

7. Щавелева Е.Н. Создания языковой среды как многокомпонентной системы / в сборнике Материалы Второй международной научно-практической конференции «Аксиологический аспект содержания непрерывного иноязычного образования: проблемы и решения», Москва, 31 января - 2 февраля 2013 г. М. 2013. С. 215-216

(с) Богданова Надежда Андреевна (Nad973@yandex.ru), Солнцева Елена Георгиевна (solntseva-elena@yandex.ru), Журнал «Современная наука: актуальные проблемы теории и практики» 